\title{
The Effects of the Atmospheric Pressure Changes on Seismic Signals or How to Improve the Quality of a Station
}

\author{
by R. Beauduin, P. Lognonné, J. P. Montagner, S. Cacho, J. F. Karczewski, and M. Morand
}

\begin{abstract}
Seismic investigations are mainly limited by seismic noise. Two microbarometers have been installed in the seismic vault of two different GEOSCOPE stations, one at SSB and the other at TAM. All vertical components and most of the horizontal components show a significant correlation with pressure. In order to correct the seismic signals from the atmospheric pressure noise, a transfer function between the pressure data and the seismic data is inverted. Results show that, after correction, the noise levels reached on the horizontal components are similar between the two stations, and the vertical components display noise levels below the lownoise model as defined by Peterson (1993). This technique reduces part of the noise and allows detection of small earthquakes and a better extraction of normal modes. The analysis of the lowest normal modes of the Earth excited by the $M_{S}=8.2$ Macquarie Island earthquake is given to illustrate the perspectives of the method.
\end{abstract}

\section{Introduction}

The background seismic noise is a limiting factor since it can mask seismic signals, especially in the low-frequency range. On the ground floor, the noise is mainly produced by temperature fluctuations, particularly for seismometers weakly thermally compensated, and, on the other hand, by atmospheric pressure fluctuations and wind. These kinds of noise perturb particularly the seismometers installed temporarily for field experiments. Taking out the buoyancy forces (which are suppressed on the vertical axis by evacuating the sensors), the pressure-generated noise is mainly produced by the elastic response of the Earth to these fluctuations. This latter noise is unavoidable (Sorrells, 1971; Sorrells et al., 1971), even if it decreases with depth. Installing the seismometers in a vault reduces these sources of noise. However, a significant atmospheric noise still remains at long periods. Even in a very good seismic vault such as BFO (Black Forest Observatory, Schiltach, Germany) where the pressure fluctuations are reduced by an airlock and with very low thermal variations (a few mK, Richter et al., 1995), pressure noise remains observable and is produced by the gravitational changes induced by cold and hot atmospheric fronts (Müller and Zürn, 1983). For cost reasons, the construction of such an ideal seismic vault is not always possible. It is even sometimes just impossible, as for seismic stations deployed in hostile environments such as deserts, ocean bottoms (Montagner et al., 1994a, 1994b), or surfaces of telluric planets (Chicarro et al., 1993; Solomon et al., 1991; Lognonné and Mosser, 1993), where a simple wind shield is the only available protection (Lognonné et al., 1996).
In order to study the possibility to suppress part of the noise by utilizing other environmental measurements of temperature and pressure, a microbarometer was installed at two stations of the GEOSCOPE network (SSB, France and TAM, Algeria). We observe that seismic data are strongly correlated to atmospheric pressure data at station SSB. At station TAM, the correlation is much lower but still significant. Our goal is to find a method that will remove the pressure noise from the seismic data. And finally, we apply this method to a large earthquake (Macquarie Island, 23 May 1989) in order to observe normal modes masked by the atmospheric pressure noise in the frequency range 0 to $2.5 \mathrm{mHz}$.

\section{Influence of the Local Site}

The seismic vault of the SSB station $\left(45.28^{\circ} \mathrm{N}, 4.54^{\circ} \mathrm{E}\right.$, elevation: $700 \mathrm{~m}$ ) is located in the middle of an old railway tunnel bored under a granite mountain of about $40-\mathrm{m}$ high. The tunnel has a length of approximately $300 \mathrm{~m}$. It is closed on one side, and there is a door on the other. The vault where the horizontal components are installed is located behind two doors, which are not hermetically closed and thus do not act as a good airlock. Atmospheric pressure changes may directly perturb the seismometers. Three microbarometers were installed inside the tunnel, one at each extremity of the tunnel and one near the entrance of the vault (Fig. 1). The microbarometers (type MIBA 279), designed by Streckeisen $\&$ Co. Messgeräte, measures air pressure variations between $0.1 \mathrm{mHz}$ and $0.01 \mathrm{~Hz}$. Pressure data have been recorded since December 1988 at a sampling rate of 1 sample/sec. It 


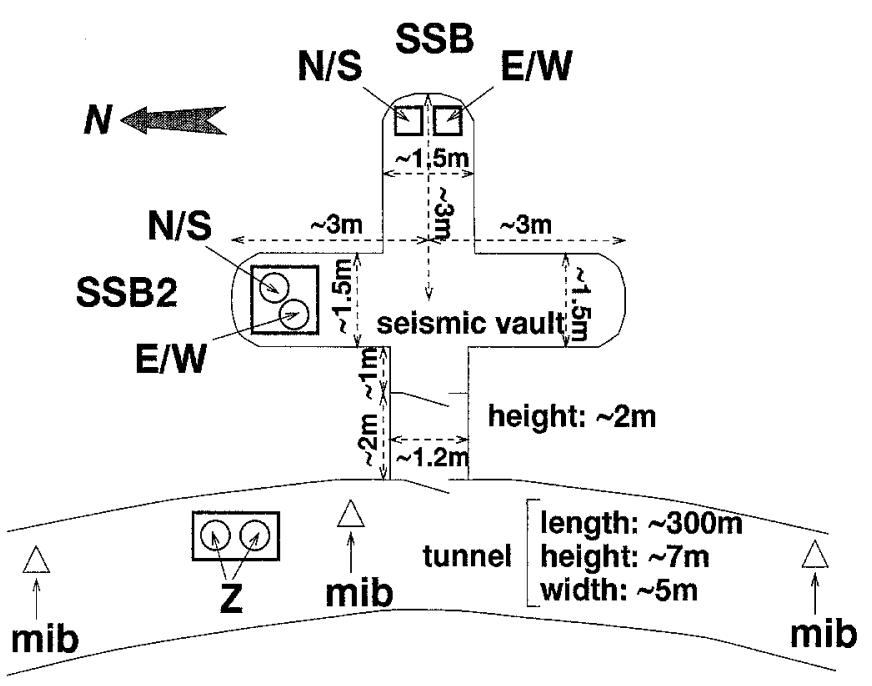

Figure 1. Map of the seismic vault of the SSB site from 16 December 1988 till 19 September 1989. In May 1990, the SSB seismometers have been moved from the east branch to the north branch of the vault.

was found that there was no difference between the three output records of the microbarometers. Therefore, only the microbarometer close to the entrance of the vault has been functional since September 1989. Unfortunately, it was out of order from February 1990 till November 1991. At the same time, two sets of three-component STS-1 seismometers were operating, later respectively referred to as SSB and SSB2. SSB was an old broadband station where the $120-\mathrm{sec}$ high-pass filter was shifted to $360 \mathrm{sec}$. SSB2 was a new very broadband station, with the same 360-sec high-pass filter. Only the integrators, the electronics of the force balance, were different. SSB2 has been installed in order to compare the output records with those of SSB. SSB2 also ensured the continuity of the records when SSB was temporarily stopped. The four horizontal seismometers were installed in the seismic vault, while the two vertical seismometers were installed in the middle of the tunnel on a concrete pillar. The SSB2 horizontal seismometers were protected by a styrofoam casing covered inside and outside with some aluminum foil to avoid thermal variations. The place where the SSB horizontal seismometers were installed was too narrow to install such a protection. Only the vertical components were evacuated. It was surprisingly observed that evacuating the horizontal seismometers increases significantly the noise, unlike the vertical components. This was also observed by Holcomb and Hutt (1992). The reason they invoke is that a sealed bell jar causes the glass plate to bend, and the atmospheric pressure variations generate tilt noise.

In December 1988, the horizontal components of SSB were installed in the east branch of the vault on two different marble slabs, while those of SSB2 were installed in the north branch on a single marble slab (Fig. 1, Table 1). All the horizontal components were installed on a glass plate that was placed on a sandbed. The average noise level of SSB is similar to those of most of the stations studied in Peterson's report on background seismic noise (Peterson, 1993). Significant pressure fluctuations are, however, observed in the vault, about $10^{-0.31} \mathrm{mbar} / \mathrm{Hz}^{1 / 2}$ at $1 \mathrm{mHz}$ and $10^{-1.18} \mathrm{mbar} /$ $\mathrm{Hz}^{1 / 2}$ at $10 \mathrm{mHz}$ (Fig. 2). The seismic noise level is roughly the same on SSB2 N and E and on SSB N, while SSB E displays a seismic noise level much lower. This component corresponds to a typical noise according to Peterson (1993) for wind-free periods. We think that this is due to a different installation of the two sets of horizontal seismometers. SSB $\mathrm{N}$ is much more sensitive to the atmospheric pressure variations than SSB E, despite the fact that they have the same kind of installation, which is on sandbed. The study of the polarization (a N/S polarization for the SSB set and a N $45^{\circ}$ polarization for the SSB2 set) and the fact that SSB E has a low noise level compared to SSB N or SSB2 E and N suggests that there might be a direct effect that makes the seismometers SSB N, SSB2 E, and SSB2 N sensitive to atmospheric pressure variations, possibly related to a small tilt of the instruments. In September 1989, SSB2 was definitively stopped and removed. SSB was still installed in the east branch of the seismic vault. In February 1990, SSB N was stopped temporarily for technical reasons and has been reinstalled in May 1990 in the north branch of the vault on a brass trivet. SSB E has been moved from the east branch and installed in the north branch on the same marble slab with a sandbed installation. We observed a slight decrease of the seismic noise level of SSB N as compared with SSB2 N or to SSB $N$ when installed in the east branch of the vault and no change of the seismic noise level of SSB E as compared with SSB2 $\mathrm{E}$ but an increase of the noise level as compared with the former SSB E. In March 1991, a new improvement was performed on SSB $E$ due to the change of the installation to a brass-trivet installation, convincing us in the fact that such an installation decreases the seismic noise as compared to a sandbed installation. The new mean levels $(-138.6 \mathrm{~dB}$ at $1 \mathrm{mHz}$ and $-160.4 \mathrm{~dB}$ at $10 \mathrm{mHz}$ ) put now the SSB horizontal noise below the mean horizontal noise during nonwindy periods. Since May 1990, the seismic noise level has decreased at $1 \mathrm{mHz}$ and $10 \mathrm{mHz}$ for SSB E, while it has remained constant for SSB N. During all these changes, the vertical seismometers have held a low seismic noise level and appear much less perturbed by the atmospheric pressure changes than the horizontal devices.

At station TAM, the seismic vault is located in the C.R.A.A.G. observatory $\left(22.79^{\circ} \mathrm{N}, 5.53^{\circ} \mathrm{E}\right.$, elevation: 1377 $\mathrm{m}$ ) and is dug into the ground. It has a ceiling of $1.3 \mathrm{~m}$ thick. A set of three STS-1 seismometers is installed on a large concrete pillar. The devices are installed on a glass plate that is placed on a sandbed. The seismometers are also covered by a thermal protection similar to those of SSB. A microbarometer is also installed on the pillar since March 1990. The installation has never been changed.

We first study the stability of correlation between pressure and seismic noise with time and invert for the transfer 
Table 1

History of the Station for the Different Installations

\begin{tabular}{|c|c|c|c|c|}
\hline $\begin{array}{c}\text { Date } \\
(\mathrm{mo} / \mathrm{dy} / \mathrm{yr})\end{array}$ & Station & $\begin{array}{l}\text { Kind of } \\
\text { Installation }\end{array}$ & $\begin{array}{l}\text { Location in } \\
\text { the Vault }\end{array}$ & Comments \\
\hline $\begin{array}{l}12 / 16 / 1988 \\
\text { to } \\
05 / 15 / 1990\end{array}$ & SSB & sandbed & east branch & $\begin{array}{l}\text { horizontal seismometers installed on two different } \\
\text { marble slabs; N/S seismometer stopped on } \\
\text { 02/13/1990 }\end{array}$ \\
\hline $\begin{array}{l}12 / 16 / 1988 \\
\text { to } \\
09 / 19 / 1989\end{array}$ & SSB2 & sandbed & north branch & $\begin{array}{l}\text { horizontal seismometers installed on the same } \\
\text { marble slab; station stopped definitively on } \\
09 / 19 / 1989\end{array}$ \\
\hline $\begin{array}{l}05 / 15 / 1990 \\
\text { to } \\
03 / 18 / 1991\end{array}$ & SSB & $\begin{array}{c}\text { sandbed }(\mathrm{E} / \mathrm{W}) \\
3 \text { brass feet }(\mathrm{N} / \mathrm{S})\end{array}$ & north branch & $\begin{array}{l}\text { N/S seismometer reinstalled in the north branch; } \\
\text { E/W seismometer moved to the north branch }\end{array}$ \\
\hline $\begin{array}{c}\text { Since } \\
03 / 18 / 1991\end{array}$ & & 3 brass feet & & horizontal seismometers are installed likewise. \\
\hline
\end{tabular}
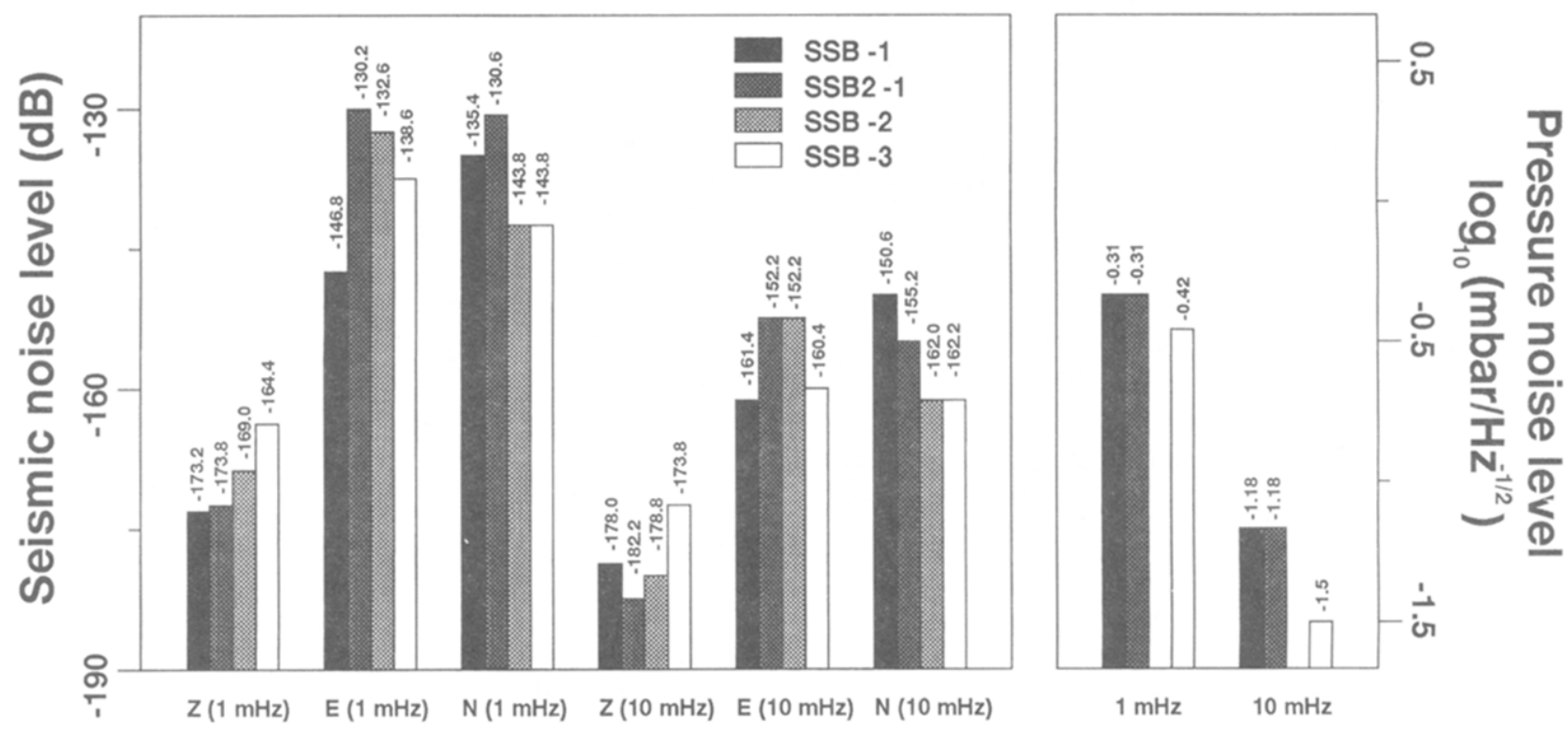

Figure 2. Average seismic noise level and average atmospheric noise level at $1 \mathrm{mHz}$ and $10 \mathrm{mHz}$ for the different kind of installations before any correction. (The microbarometer was not operating from February 1990 till November 1991.) (SSB-1: from 12/16/1988 to 05/15/1989; SSB2-1: from $12 / 16 / 1988$ to $09 / 19 / 1989$; SSB-2: from $05 / 15 / 1990$ to $03 / 18 /$ 1991; SSB-3: from 03/18/1991 to $12 / 31 / 1992$.)

function. We finally show that this noise can be removed in order to increase the signal-to-noise ratio of seismic events.

\section{Coherence between Seismic Noise and Atmospheric Pressure}

We used the coherence function defined by Bendat and Piersol (1986) as

$$
\gamma_{S, P}^{2}(\omega)=\frac{\left|E\left[S^{*}(\omega) \cdot P(\omega)\right]\right|^{2}}{E\left[|S(\omega)|^{2}\right] \cdot E\left[|P(\omega)|^{2}\right]},
$$

where $S(\omega)$ and $P(\omega)$ are, respectively, the Fourier transform of the observed seismic signal $s(t)$ and the atmospheric pressure field $p(t) ; S^{*}(\omega)$ is the complex conjugate of $S(\omega)$; and $E[|S(\omega)|]$ is the average ensemble or expected value of the function $S(\omega)\left(E[|S(\omega)|]=(1 / N) \sum_{k=1}^{N}\left|S_{k}(\omega)\right|\right.$, where $S(\omega)$ is divided into $N$ intervals.). The coherence is calculated between the microbarometric pressure data (mib) and the seismic data (VLP) of the three components for the days where data are available for both channels. Each independent record has a length of $24 \mathrm{hr}$ that is divided into four intervals of $6 \mathrm{hr}$ to be able to calculate the average ensembles. Figure 3 shows an example of coherence between the seismic noise of the three components and the pressure noise 

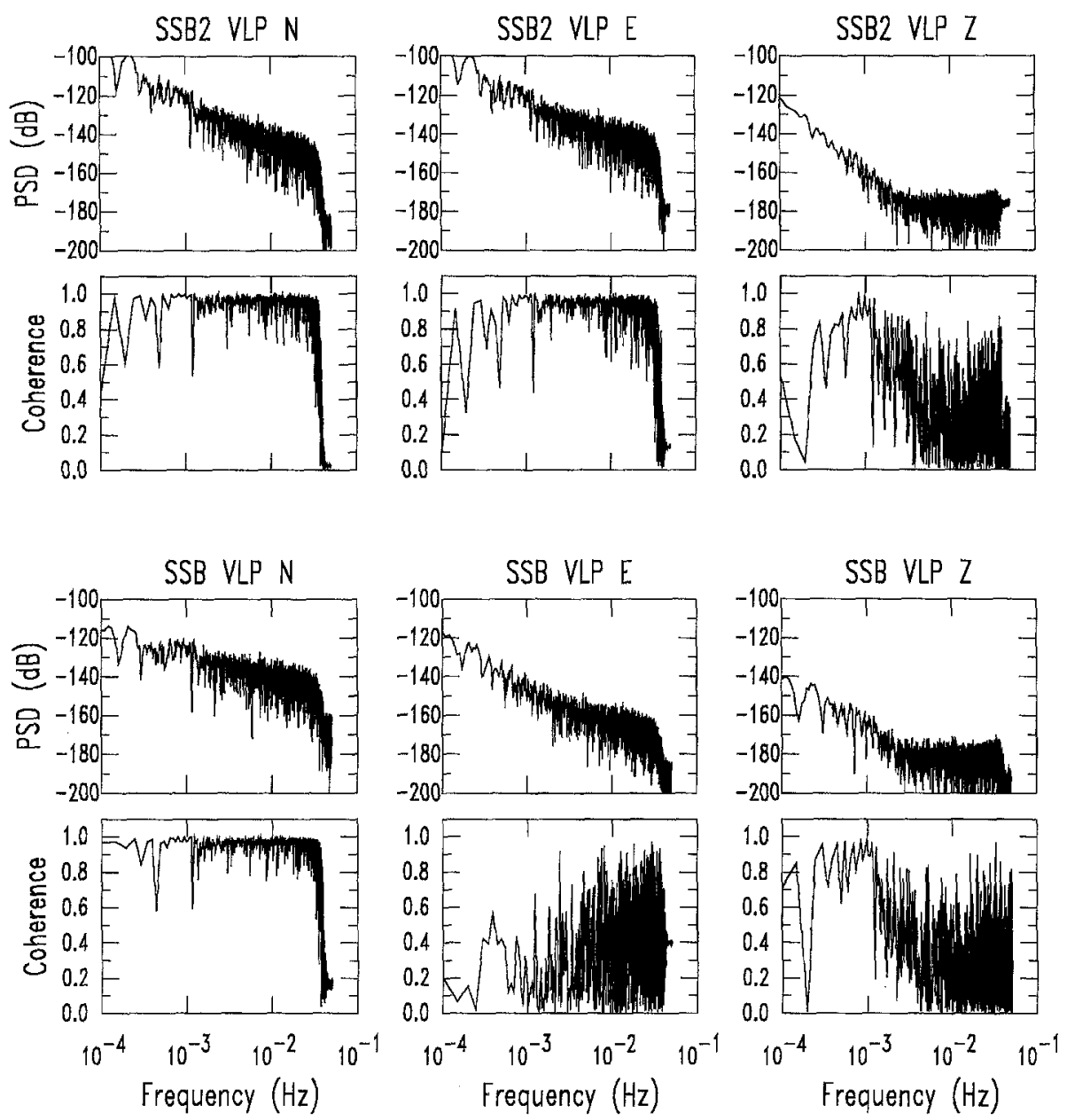

Figure 3. Coherence between pressure and seismic data recorded at stations SSB and SSB2 for the three components (16 August (228) 1989) and power spectral densities of seismic noise [in $\mathrm{dB}\left(10 \log _{10}\left(\mathrm{~m}^{2} / \mathrm{sec}^{4} / \mathrm{Hz}\right)\right)$ referred to $1 \mathrm{~m}^{2} / \mathrm{sec}^{4} / \mathrm{Hz}$ ]. We observe a good coherence for SSB N and SSB2 N and E. Surprisingly, SSB E is not well correlated to the atmospheric pressure despite the closeness of the two devices of SSB and displays a seismic noise level lower than SSB N or SSB2 E and N. The vertical components of SSB and SSB2 are not as well correlated to the pressure variations and display a noise level much lower than the horizontal components.

for a particular day, day 228,1989 , and the power spectral densities of the three seismic components. The coherence is very high on all horizontal components except the east-west component of SSB. The power spectra of these components show that the noise level of SSB E is the lowest. That is quite surprising, despite the closeness of the seismometers, but if considering a direct effect as explained above, SSB E may be much less sensitive to pressure variations. The vertical components are not as well correlated as the horizontal components of SSB 2 or SSB N.

Figure 4 shows three coherograms between the pressure data and the seismic data of (a) the north-south component of SSB2 (1989), (b) the east-west component of SSB (1989), and (c) the north-south component of SSB (1992). Gray areas correspond to days where either atmospheric pressure data or seismic data are not available. The coherence is cal- culated for every day ( $24 \mathrm{hr}$ ) just as in Figure 3 . When looking at the coherogram of SSB2 N (1989) (Fig. 4a), the coherence between seismic data and atmospheric pressure field is very high (between 0.8 and 1) at frequencies lower than about $0.03 \mathrm{~Hz}$. The more the pressure noise, the more the seismic noise, and thus, the coherence increases. Such coherences are also observed on SSB N and SSB2 E. On Figure $4 \mathrm{~b}$, the coherence on SSB E is very low most of the time (between 0 and 0.4), except for some days for which pressure fluctuations reach stronger amplitudes. When the microbarometer is operating again in November 1991, a high coherence between 0.8 and 1 is observed for the horizontal components of SSB in 1992, as seen on Table 2 and Figure $4 \mathrm{c}$. The vertical components of the seismic noise are correlated to the atmospheric pressure changes only at long periods, between 0.3 and $2 \mathrm{mHz}$. Note that these good corre- 


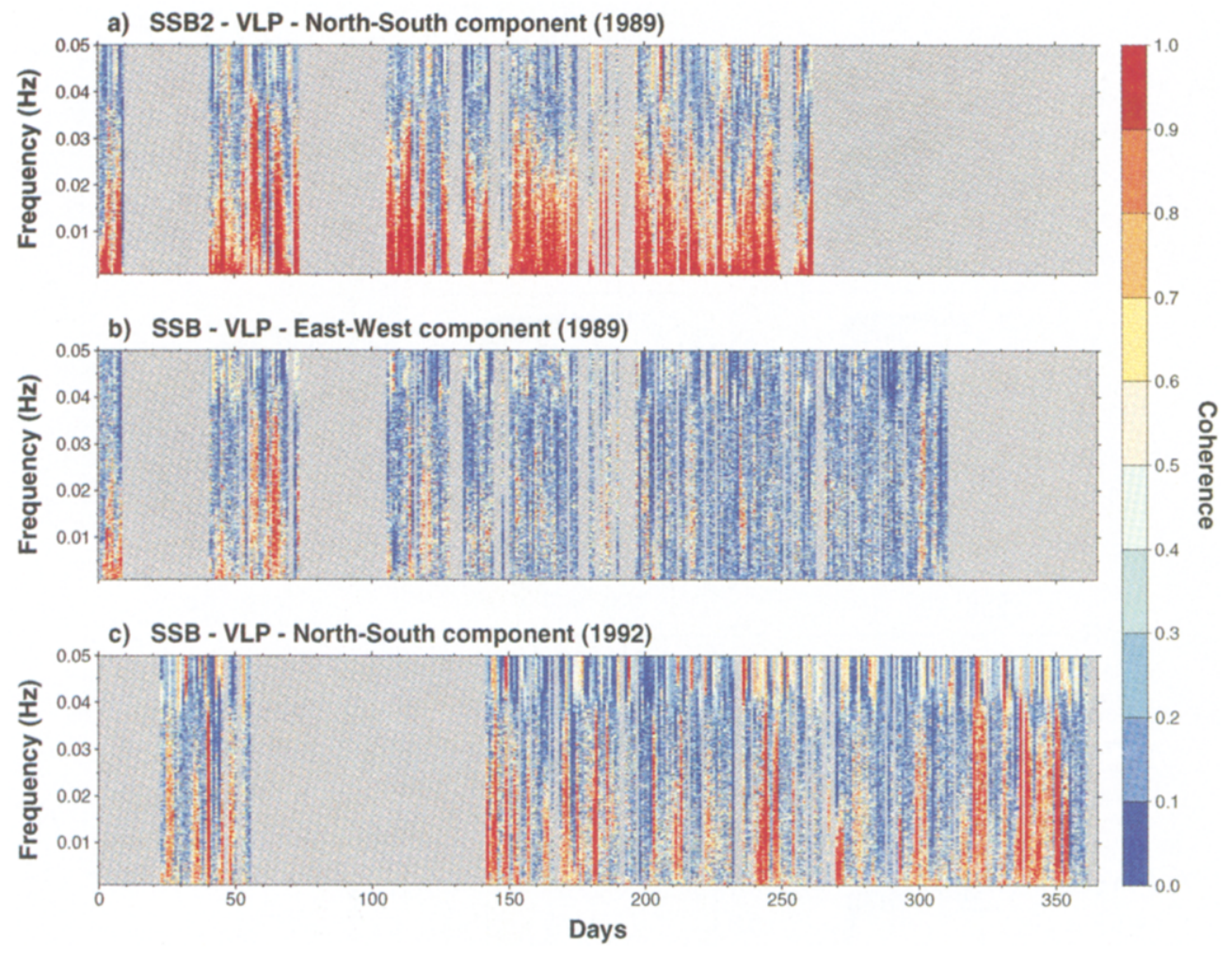

Figure 4. (a) Coherogram between SSB2 N seismic noise and pressure noise (1989). The coherence is often between 0.9 and 1 (red areas) in the frequency range 0 to 30 $\mathrm{mHz}$. A few days have a low coherence level. (b) Coherogram between SSB E seismic noise and pressure noise (1989). Unlike SSB2 $\mathrm{N}$, the coherence is most of the time lower than 0.3 and sometimes greater than 0.9 . (c) Coherogram between SSB N seismic noise and pressure noise (1992).

lations are not observed every day and depends on the atmospheric conditions.

At station TAM located in the Sahara desert, it is clearly observed on the seismograms that high-frequency noise is perturbing the seismic data only during the day, and at night, that noise is not observed. It is probably due to temperature fluctuations between night and day. And we also observe a coherence between the seismic data and the atmospheric pressure data even if the seismic data are not as well correlated to pressure variations as for the station SSB.

\section{Improvement of the Signal-to-Noise Ratio}

\section{Method}

As shown in the previous section, all the SSB, SSB2, and TAM components, to different levels, are sensitive to the pressure fluctuations, at least for some days. In order to remove the signal associated to atmospheric pressure from the observed seismic signal, the transfer function $\tilde{a}$ between the pressure data and the seismic data was inverted for by minimizing the coherence between the pressure signal $P(\omega)$ and the pressure-corrected seismic signal $S(\omega)-\tilde{a}(\omega) \cdot P(\omega)$; that is,

$$
\gamma_{S-\tilde{a} \cdot P, P}^{2}(\omega)=\frac{\mid E\left[(S(\omega)-\tilde{a}(\omega) \cdot P(\omega))^{*} \cdot P(\omega)\right]^{2}}{E\left[|S(\omega)-\tilde{a}(\omega) \cdot P(\omega)|^{2}\right] \cdot E\left[|P(\omega)|^{2}\right]}
$$

must be minimal. The complex transfer function $\tilde{a}$ is then found for all frequencies. The transfer function was first calculated for every day when the coherence is significant, and it turned out that the amplitude and phase of these transfer functions were not varying with time. Therefore, we selected seismic data of length of $24 \mathrm{hr}$ containing no large earthquake and well correlated with pressure data in order to calculate a single transfer function by least-squares fitting. An inverse Fourier transform gives us the predicted signal $s^{\prime}(t)=s(t)-a(t) * p(t)$. Figure 5 shows an example of such transfer functions for the year 1989 after selecting 100 days for SSB. Note that the SSB E and SSB Z transfer function phases are oscillating very much from a few $\mathrm{mHz}$ till Nyquist frequency, while SSB N is much more stable in frequency. The pressure noise generated on the N/S component might be a direct effect of the atmospheric pressure, while, on the $\mathrm{E} / \mathrm{W}$ component, it might be a site effect, and on the vertical components, the noise is probably related to the change in gravitational attraction of the atmosphere. 
Table 2

Average Coherence between the Horizontal Components and the Atmospheric Pressure Field (APF)

\begin{tabular}{|c|c|c|c|c|c|}
\hline \multirow{2}{*}{$\begin{array}{c}\text { Date } \\
\text { (mo/dy/yr) }\end{array}$} & \multirow[b]{2}{*}{ Station } & \multicolumn{2}{|c|}{ Coherence N/S-APF } & \multicolumn{2}{|c|}{ Coherence E/W-APF } \\
\hline & & $1 \mathrm{mHz}$ & $10 \mathrm{mHz}$ & $1 \mathrm{mHz}$ & $10 \mathrm{mHz}$ \\
\hline $\begin{array}{c}12 / 16 / 1988 \\
\text { to } \\
05 / 15 / 1990\end{array}$ & SSB & 0.73 & 0.77 & 0.47 & 0.40 \\
\hline $\begin{array}{c}12 / 16 / 1988 \\
\text { to } \\
09 / 19 / 1989\end{array}$ & SSB2 & 0.92 & 0.76 & 0.91 & 0.74 \\
\hline $\begin{array}{c}05 / 15 / 1990 \\
\text { to } \\
03 / 18 / 1991\end{array}$ & SSB & - & 一 & - & - \\
\hline $\begin{array}{c}03 / 18 / 1991 \\
\text { to } \\
12 / 31 / 1992\end{array}$ & SSB & $0.5^{*}$ & $0.44 *$ & $0.84^{*}$ & $0.46^{*}$ \\
\hline
\end{tabular}

*The microbarometer was not operating from February 1990 till November 1991.

\section{Atmospheric Pressure Field Removed} from Seismic Data

By using the inverted frequency-dependent transfer function for SSB and SSB2 as explained in the previous section, it is now possible to apply a correction on the seismic data. Figure 6 shows an example of raw seismic data perturbed by the fluctuations of the atmospheric pressure field, containing two earthquakes of magnitude $M_{S}=6$ and 6.8, whose characteristics are listed in Table 3 . We note the predominance of the pressure-induced noise. By removing these fluctuations, the earthquakes are now largely above noise level. The original data, strongly correlated with the atmospheric pressure changes in the period range 100 to $1000 \mathrm{sec}$, has a seismic noise level decreased after correction by about
$20 \mathrm{~dB}$. This correction can be performed routinely on seismic data.

Figure 7 shows the average noise level at stations SSB and SSB2 (1989) and TAM (1994) before and after correction of the atmospheric pressure. We can see that the correction is significant especially for SSB2, where the correction is better at low frequencies (at $1 \mathrm{mHz}$, about $-12 \mathrm{~dB}$; at 10 $\mathrm{mHz}$, about $-6 \mathrm{~dB}$ ). For SSB, the correction is still good for the north-south component (at $1 \mathrm{mHz}$, about $-4.7 \mathrm{~dB}$; at $10 \mathrm{mHz}$, about $-7.7 \mathrm{~dB}$ ). For the east-west component of SSB, the correction is very small, which is not surprising because we did not observe any high coherence between seismic data and atmospheric pressure data. Despite the low coherences at TAM and SSB2 Z, it is, however, possible to suppress part of the noise related to pressure variations. The horizontal components of TAM are much less corrected (by $5 \mathrm{~dB}$ or less), while the vertical components (TAM $\mathrm{Z}$ and SSB2 Z) display noise levels after correction lower than the new low-noise model (NLNM) as defined by Peterson (1993), confirming recent results of Zürn and Widmer (1995). After correction, the four horizontal components display roughly the same noise levels, showing the efficiency of the procedure to correct noise eventually of different type. In all cases, the correction does not affect the shape of the long-period noise spectrum. All noise spectra are in $1 / \omega$, and the correction only increases the width of the long-period low-noise window, which is extended up to $10 \mathrm{mHz}$, still one decade less than the vertical one's. This long-period noise may be related to remaining temperature variations, which cannot be filtered by the thermal protection of the seismometers. That noise may also be related to instrument transducer noise. Indeed, all the vertical components display a noise level of about $-150 \mathrm{~dB}$ at $10^{-4} \mathrm{~Hz}$, which might be the limit of the resolution of the instrument (see Peterson, 1993, p. 16-20). This shows that improvement of the VBB
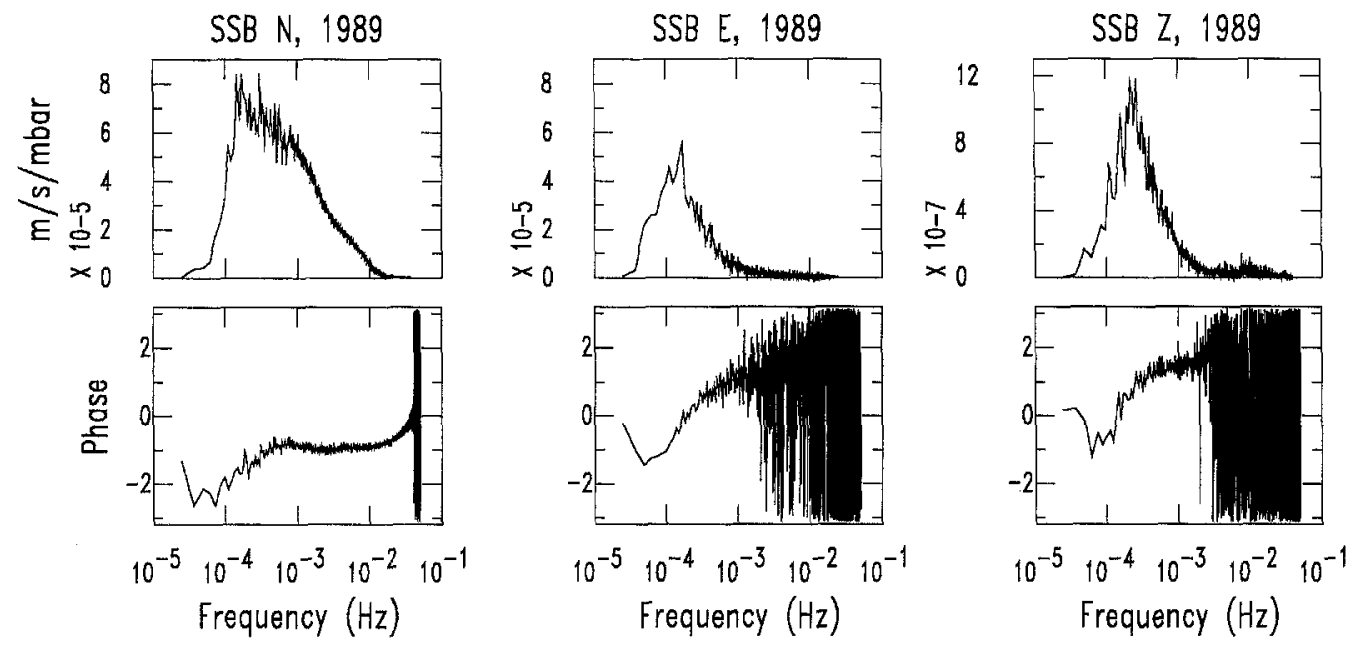

Figure 5. Amplitude and phase of the transfer function $\tilde{a}$ for the three components (station SSB). 

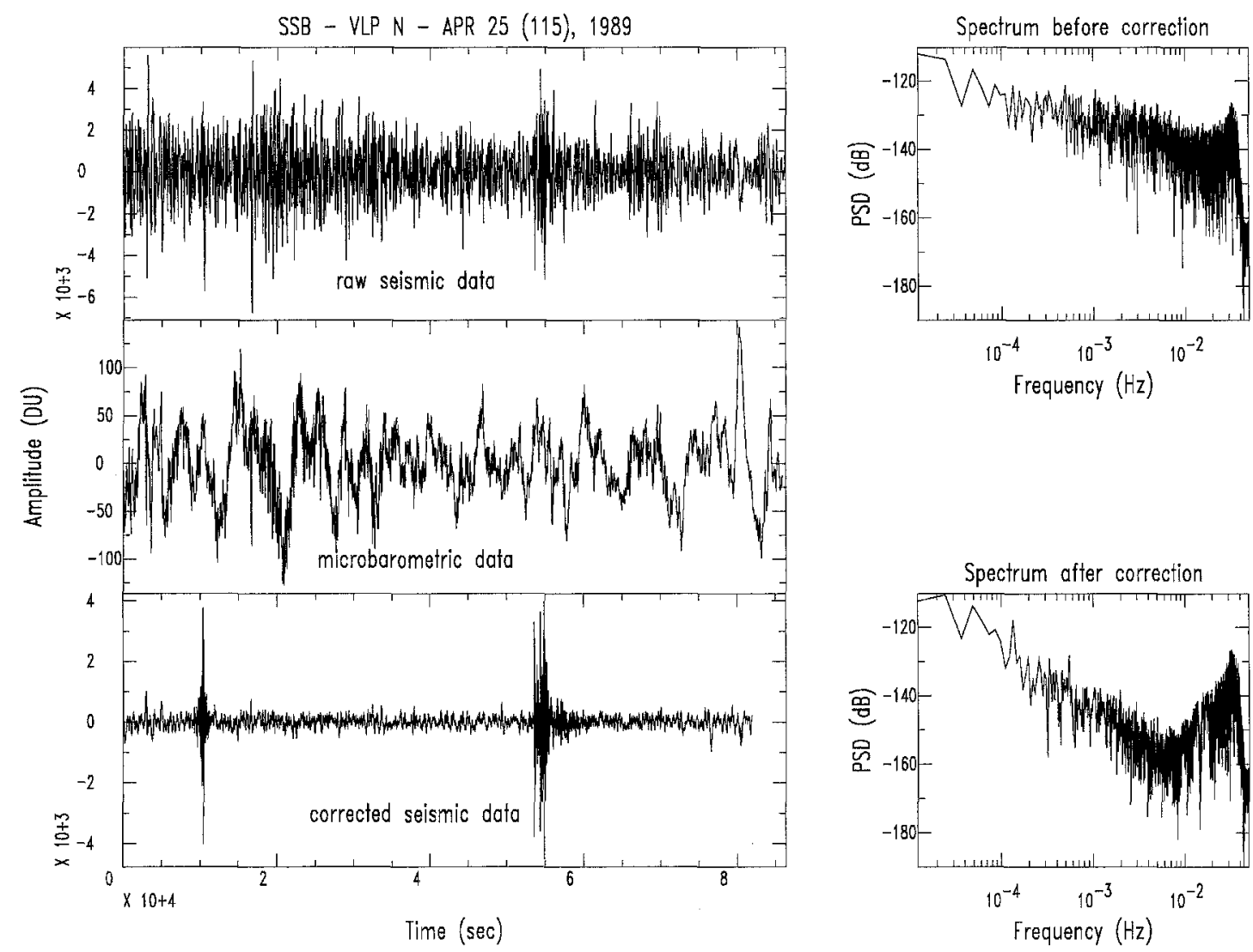

Figure 6. Example of two earthquakes hidden by the atmospheric pressure noise (top). The bottom seismogram shows these two earthquakes after removing the pressure noise (middle) (25 April (115) 1989) at station SSB. On the right side are plotted the corresponding power spectral densities calculated before and after correction. A decrease of about one decade $(20 \mathrm{~dB})$ is observed on the frequency range 1 to $10 \mathrm{mHz}$.

Table 3

Information on Earthquakes Recorded on 25 April 1989

\begin{tabular}{|c|c|c|c|c|c|c|}
\hline Region & Origin Time & Latitude & Longitude & Depth & $M_{b}$ & $M_{s}$ \\
\hline Sichuan Province, China & $02 \mathrm{~h} 13^{\prime} 20.8^{\prime \prime}$ & $30.048^{\circ} \mathrm{N}$ & $99.419^{\circ} \mathrm{E}$ & $8 \mathrm{~km}$ & 6.2 & 6.0 \\
\hline Near Coast of Guerrero, Mexico & $14 \mathrm{~h} 29^{\prime} 00.5^{\prime \prime}$ & $16.773^{\circ} \mathrm{N}$ & $99.328^{\circ} \mathrm{W}$ & $19 \mathrm{~km}$ & 6.2 & 6.8 \\
\hline
\end{tabular}

seismometer at normal-mode frequencies will be useful for better observations.

\section{Extraction of the Normal Modes of the Earth}

In the very long-period range, the pressure correction appears to be very efficient in restoring a good signal-tonoise ratio for the horizontal east-west and north-south spheroidal and toroidal modes. As an example, we have chosen the largest earthquake that occurred in 1989, the Macquarie Island earthquake (23 May 1989-10h54'46.3'- $M_{S}$ $=8.2$ ). By applying the frequency-dependent transfer function to this earthquake, it is now possible to observe the lowest toroidal normal modes of the Earth in the frequency band 0.3 to $1.4 \mathrm{mHz}$ that where not visible before removing the atmospheric pressure field, such as ${ }_{0} T_{3},{ }_{0} T_{4},{ }_{0} T_{5}, \ldots$ (Fig.
8). The signal-to-noise ratio has increased considerably. In the frequency band 1.4 to $2.2 \mathrm{mHz}$, peaks such as ${ }_{1} T_{3}(1.44$ $\mathrm{mHz}),{ }_{1} T_{6}(1.92 \mathrm{mHz})$, or ${ }_{2} S_{8}(2.05 \mathrm{mHz})$ are arising above the noise level (Fig. 9). A time window of $70 \mathrm{hr}$ starting 2 hr after the beginning of the earthquake has been used here to compare with the data recorded at station BFO, considered as one of the best stations in the world (Richter et al., 1995). No rotation of the initial horizontal components has been done because of an epicentral distance of $162.7^{\circ}$, too close to $180^{\circ}$. Correction of the atmospheric pressure noise can be observed up to $4 \mathrm{mHz}$.

Figures 8 and 9 show also the spectra of the same earthquake recorded at station BFO by a set of three-component STS-1 prototype seismometers. These data are not corrected from the atmospheric pressure variations. We can observe 

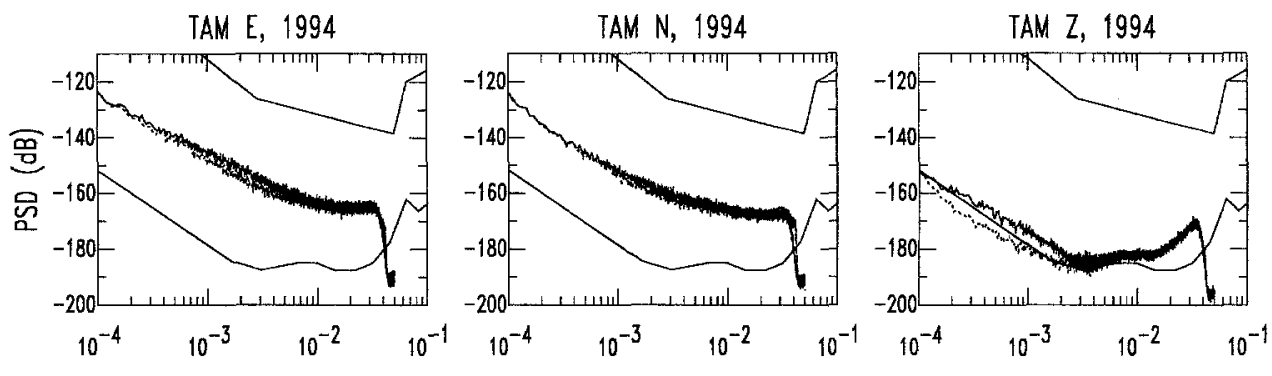

SSB2 E, 1989
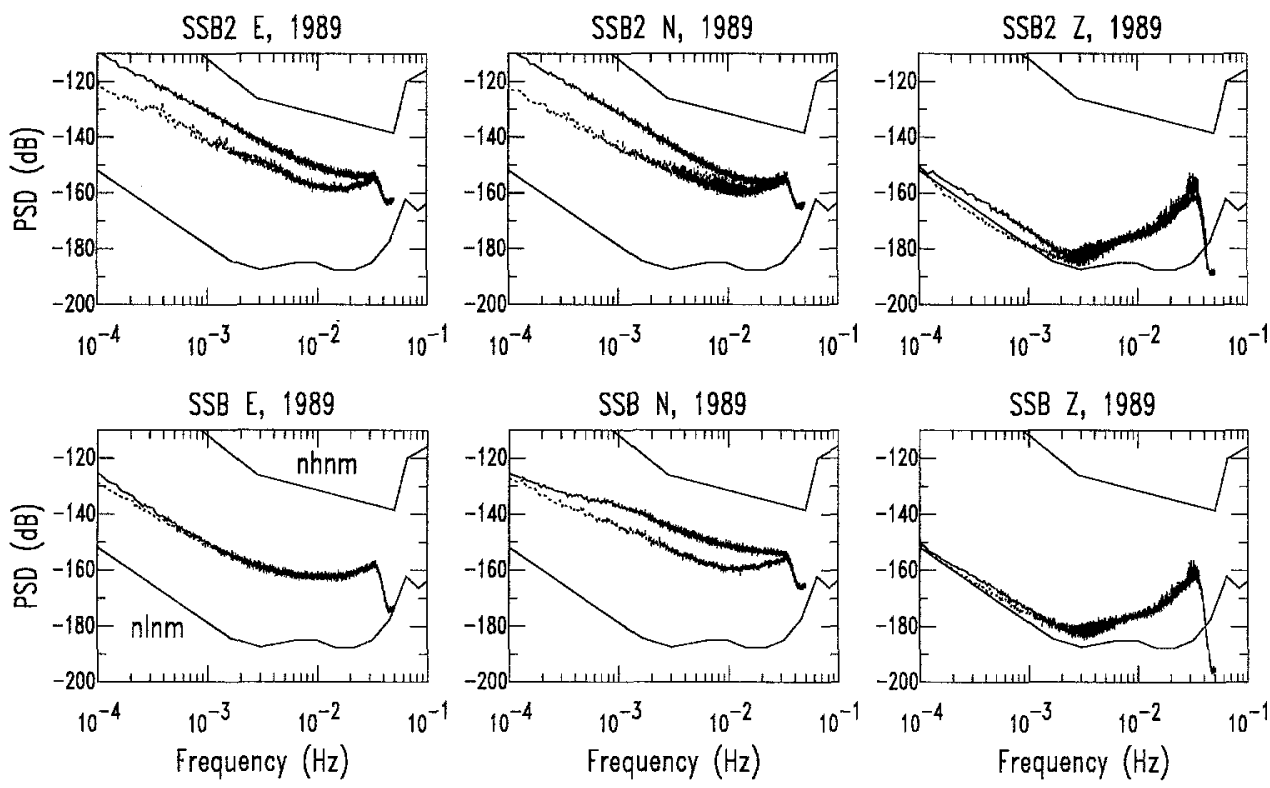

Figure 7. Comparison between the average seismic noise level before and after correction of the atmospheric pressure noise at stations SSB, SSB2 (1989), and TAM (1994). The upper (nhnm) and lower (nlnm) curves correspond to the high- and low- noise models of Peterson (1993).

that the signal-to-noise ratio is much higher at SSB Z or SSB2 $\mathrm{Z}$ than at $\mathrm{BFO} \mathrm{Z}$ in the frequency range 0.3 to $1.4 \mathrm{mHz}$ (due probably to instrumental noise of the Wielandt seismometers) and slightly higher at SSB N or SSB2 N than at BFO N. For the east-west component, $\mathrm{BFO}$ gives much better results than SSB or SSB2 after the pressure correction. Note that ${ }_{0} T_{3}$ appears slightly over the noise at BFO E and SSB2 N. In the frequency band 1.4 to $2.2 \mathrm{mHz}$ (Fig. 9), the signal-to-noise ratio of $\mathrm{BFO} \mathrm{N}$ has increased and is higher than at $\mathrm{SSB}$ or SSB2, and BFO E is still better.

\section{Conclusions}

We showed in this article that, even in a seismic vault, a seismometer can be perturbed by the effects of the atmospheric pressure changes. Unfortunately, this effect is not systematic and varies in time and space. A transfer function has been calculated to minimize the coherence between the observed seismic data and the atmospheric pressure field. When applying this transfer function to the seismic data, we obtained clean signals with no atmospheric disturbances. The mean average noise level is decreased by $12 \mathrm{~dB}$ for the horizontal components of SSB2. For some particular days, the spectral amplitudes may decrease to about $20 \mathrm{~dB}$, while the amplitudes of the time series are lowered by a factor of about 20. This method enables us to observe some seismic signals hidden by the atmospheric pressure noise, such as remote quakes or peaks of spheroidal and toroidal normal modes. This method applied to the seismic data recorded at station TAM gives less results compared to those of SSB or SSB2 because the atmospheric pressure fluctuations are smaller at this site, and part of the seismic noise has a cultural origin. The more seismic data are correlated to pressure, then the more this method removes atmospheric pressure noise, and the more efficient is the method. Surprisingly, some instruments, or some sites in the vault, display a very small sensitivity. When this sensitivity is not related to the instrument, this suggests that the installation of the horizontal sensors may require a mapping of the horizontal noise level in the vault, in order to select the best location. This seams to be valid even at periods where the wavelength of seismic waves are orders of magnitude greater than the vault dimensions.

However, neither installation nor site suppress totally this pressure-induced noise. Coupling microbarometric mea- 

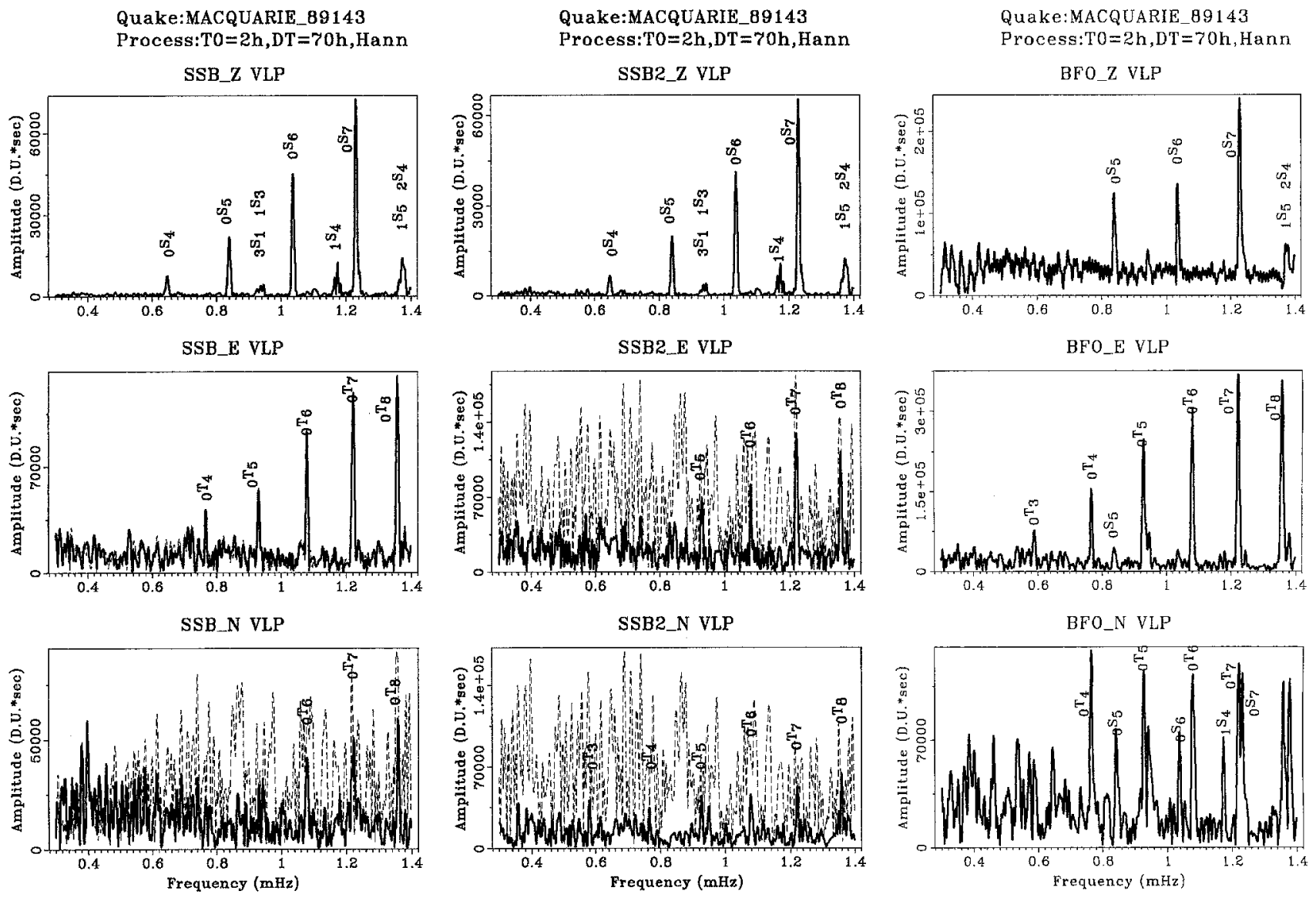

Figure 8. Spectra of the Macquarie Island earthquake for the three components of SSB, SSB2, and BFO showing the normal modes of the Earth before (dashed line) and after (solid line) correction of the atmospheric pressure noise in the frequency band 0.3 to $1.4 \mathrm{mHz}$. The data recorded at $\mathrm{BFO}$ are not corrected from pressure noise. The vertical components are not affected by the correction because they are well protected against atmospheric pressure variations. Some normal modes, such as ${ }_{0} T_{3},{ }_{0} T_{4},{ }_{0} T_{5},{ }_{0} T_{6},{ }_{0} T_{7}$, and ${ }_{0} T_{8}$, that were hidden by the atmospheric pressure noise appear in the spectra after correction.

surement with seismic signals may improve significantly the quality of long-period seismic records in most of the global seismic stations, and the deployment of microbarometers must be planned in the future.

This experiment is a first attempt to demonstrate the utility for simultaneously recording different physical parameters. In particular, it is shown that the pressure recording makes it possible in the worst cases to decrease the noise level, and in the best cases (when no correlation is observed), it can be used as a good diagnosis for detecting good sites. The recordings of these different physical parameters might be very useful for the future stations that will be installed in hostile environments, where it is not always possible to control the installation of seismometers and modify it if necessary.

\section{Acknowledgments}

We wish to thank G. Roult, R. Nawab, P. Thmlé, P. Bernard, E. Wielandt, and the GEOSCOPE team for the fruitful discussion we had during this work,
W. Zürn for sending us the data of BFO, and two anonymous reviewers for their suggestions. Many thanks to the GEOSCOPE operators for the high quality of seismic data. This is IPGP Contribution Number 1444 and Contribution Number 5596 of the Division of Geological and Planetary Sciences, California Institute of Technology, Pasadena, California.

\section{References}

Bendat, J. S. and A. G. Piersol (1986). Random Data: Analysis and Measurement Procedures, Wiley-Interscience, New York.

Chicarro, A. F., M. Coradini, M. Fulchignoni, K. Hiller, J. M. Knudsen, I. Liede, C. Lindberg, P. Lognonné, R. Pellinen, T. Spohn, F. Taylor, G. E. N. Scoon, and H. Wänke (1993). MARSNET: Phase-A study report, ESA Pub. SCI(93)2.

Holcomb, G. L. and C. R. Hutt (1993). An evaluation of installation methods for STS-1 seismometers, U.S. Geol. Surv. Open-File Rept. $92-$ 302, Albuquerque.

Lognonné, P. and B. Mosser (1993). Planetary seismology, Surv. Geophys. 14, 239-302.

Lognonné, P., J. Gagnepain-Beyneix, B. Banerdt, S. Cacho, J. K. Karczewski, and M. Morand (1996). Ultra broadband seismology on Intermarsnet, Planet. Space Sci., in press. 

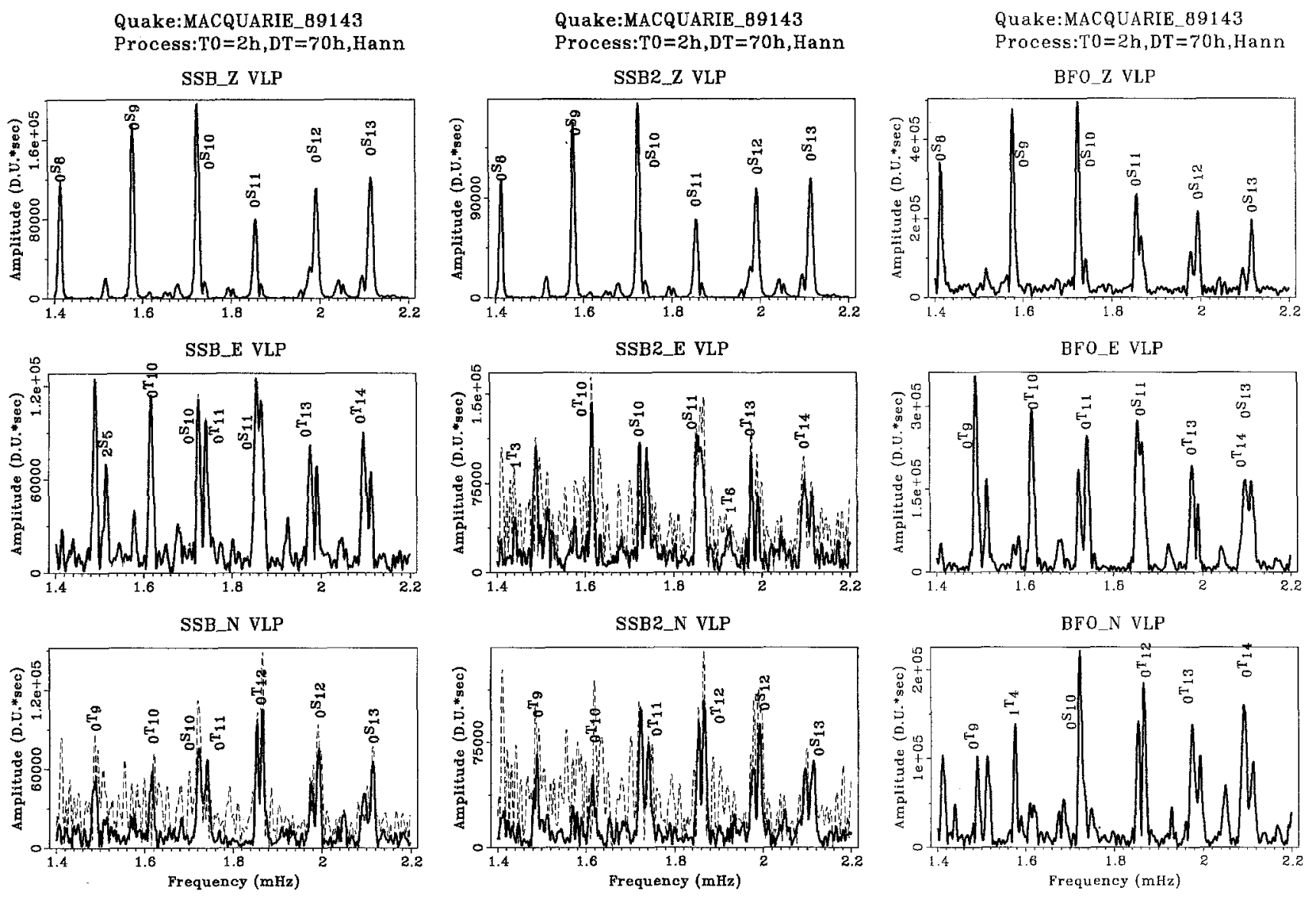

Figure 9. Same spectra as Figure 8 but in the frequency range 1.4 to $2.2 \mathrm{mHz}$. Some normal-mode peaks such as ${ }_{1} T_{3}(1.44 \mathrm{mHz}),{ }_{1} T_{6}(1.92 \mathrm{mHz})$, or ${ }_{2} S_{8}(2.05 \mathrm{mHz})$ are emerging from the noise.

Montagner, J. P., J. F. Karczewski, B., Romanowicz, S. Bouaricha, P. Lognonné, G. Roult, E. Stutzmann, J. L. Thirot, J. Brion, B. Dole, D. Fouassier, J. C. Koenig, J. Savary, L. Floury, J. Dupond, A. Echardour, and H. Floc'h (1994a). The French pilot experiment OFM/SISMOBS: first scientific results on noise level and event detection, $P$ hys. Earth Planet. Interiors 84, 321-336.

Montagner, J. P., J. F. Karczewski, and B. Romanowicz (1994b). A first

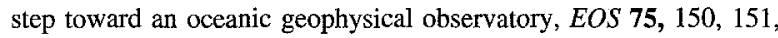
and 154.

Müller, T. and W. Zürn (1983). Observation of gravity changes during the passage of cold fronts, J. Geophys. 53, 155-160.

Peterson, J. (1993). Observation and modeling of background seismic noise, U.S. Geol. Surv. Open-File Rept. 93-322, Albuquerque.

Richter, B., H. G. Wenzel, W. Zürn, and F. Klopping (1995). From chandler wobble to free oscillations: comparison of cryogenic gravimeters and other instruments in a wide period range, Phys. Earth Planet. Interiors 91, 131-148.

Solomon, S. C., D. L. Anderson, W. B. Banerdt, R. G. Butler, P. M. Davis, F. K. Duennebier, Y. Nakamura, E. A. Okal, and R. G. Phillips (1991). Scientific rationale and requirements for a global seismic network on Mars, LPI Tech. Rept. 91-02, 51 pp.

Sorrells, G. G. (1971). A preliminary investigation into the relationship between long-period seismic noise and local fluctuations in the atmospheric pressure field, Geophys. J. R. Astr. Soc. 26, 71-82.
Sorrells, G. G., J. A. McDonald, Z. A. Der, and E. Herrin (1971). Earth motion caused by local atmospheric pressure changes, Geophys. J. R. Astr. Soc. 26, 83-98.

Zürn, W. and R. Widmer (1995). On noise reduction in vertical seismic records below $2 \mathrm{mHz}$ using local barometric pressure, Geophys. Res. Lett. 22, 3537-3540.

Département de Sismologie

Institut de Physique du Globe de Paris

CNRS, URA 195

4 Place Jussieu

75252 Paris Cedex 05, France

(R.B., P.L., J.P.M., S.C.)

Seismological Laboratory

California Institute of Technology

Pasadena, California 91125

(P.L)

DT/INSU

4 Avenue de Neptune

94107 St.-Maur-des-Fossés, France

(J.F.K., M.M.)

Manuscript received 12 May 1995. 